\title{
Female Buddhist Intellectuals with Industry 4.0 in Vietnam Today
}

\author{
PhD. Cao Thi Minh Hong \\ Nun, Thich Dieu Tam, Chief of Office cum Head of International Buddhist Department of the North Central \\ Division of Nuns
}

PhD. Lawyer. Mai Trong An Vinh

Ho Chi Minh City Bar Association

\begin{abstract}
The industrial revolution 4.0 has a strong impact on production activities, creating a great change in production methods and social life. Successfully implementing the industrial revolution 4.0 is a strategy of "going ahead, getting ahead" for Vietnam to become a "start-up" country, creating a "breakthrough" step in the process of rapid and sustainable development; affirming the position and stature of Vietnam in the region and the world. As one of the important resources of Buddhism in particular, over the years, Buddhist female intellectuals have constantly developed and made active contributions to the process of integration and development of the country and Buddhism. Therefore, in the article, the author delves deeply into clarifying the role of female Buddhist intellectuals in Vietnam for many years, thereby proposing some solutions to further promote the role of Buddhist female intellectuals. in the Industrial Revolution 4.0 in Vietnam today.
\end{abstract}

Keywords: Industry 4.0, Female intellectuals, Buddhism, Roles, Buddhism in Vietnam.

DOI: $10.7176 / \mathrm{JCSD} / 66-04$

Publication date:August $31^{\text {st }} 2021$

\section{Preamble}

The impact of the Industrial Revolution 4.0 is taking place strongly in the world, requiring countries to have their own development strategies. In recent years, the Government of Vietnam has realized the importance and launched many policies and measures to take advantage of the achievements of this revolution. One of the important policies is that Vietnam considers the construction and development of a contingent of Vietnamese intellectuals, considering this as the resource of all resources, the decisive factor in every success, so as to anticipate and take advantage of it. effective Industrial Revolution 4.0.

Most Venerable Thich Thien Nhon, Chairman of the Executive Council of the Vietnam Buddhist Sangha, Chairman of the Vesak 2019 Organizing Committee, focused on Buddhism with the approach to the industrial revolution 4.0, the world is facing. facing many conflicts, terrorism, war, inequality, environmental crisis. The rapid development of science and technology changes all aspects of social life and traditional structures, the more it is necessary to promote the core values of Buddhism. It is the spirit of tolerance, selflessness, altruism, harmony, and peace. Therefore, the Venerable Master called on the world's Buddhists to unite, engage in action in the world, and share therapeutic solutions to social challenges in the current era.

Within the framework of Vesak 2019, there was also a seminar on Buddhism with many cross-cutting contents presented such as: Buddhist approach to harmonious family; Buddhist approach to education; Buddhism and the industrial revolution 4.0; Buddhist approach to responsible consumption etc.

As the presentation "Buddhist approach to global leadership and shared responsibility for sustainable society - Industry 4.0" at Vesak 2019 conference - Tam Chuc Pagoda, Kim Bang, Ha Nam by Venerable Dr. Thich Duc Thien, Vice President and General Secretary of the Vietnam Buddhist Sangha.

"Buddhist approach to global leadership and shared responsibility for sustainable society", Vesak 2019 discusses issues, including Buddhist approach to global leadership and shared responsibility for a sustainable society, righteous leadership for sustainable peace. Especially Buddhist issues in life, such as the Buddhist approach to family harmony, sustainable health care. Buddhist approach to global moral education, industrial revolution 4.0 and Buddhism and Buddhist approach to responsible consumption and sustainable development are also mentioned.

We are at the dawn of the 4th industrial revolution or commonly known as Industry 4.0. This is a technological revolution that is expected to fundamentally change the relationship between the way people live and work. These changes in scope and complexity are unlike what humanity has known until now. We may not know what will happen in the future with this new technological revolution, but one thing is for sure, it will have a global impact. Specifically, the revolution involves all audiences as well as sectors: the public sector, the private sector, the scientific community, cultural and religious activists and civil society.

It is undeniable that the industrial revolution 4.0 has brought unprecedented success in all aspects of society. But besides those successes, this revolution has created some serious and difficult problems to solve on a global scale. such as environmental degradation, climate change, poverty and inequality. Buddhism with multi- 
dimensional appreciation across disciplines so how does Buddhism approach global leadership and shared responsibility towards a globally sustainable society.

Today, the Buddhist intellectual class is aware of the importance of 4.0 technology application, so the Resolution of the 8th National Buddhist Congress for the 2017-2022 term has highlighted the key point: "Promoting communication Communicating Buddhism as a Dharma channel and transmitting Buddhist activities into social life in order to uphold the value of Compassion - Wisdom of Buddhism, the good image of monks, nuns, and Buddhists, of the organization. Churches at all levels in the cause of patriotic service, construction and defense of the Socialist Vietnamese Fatherland" ${ }^{I}$. Female Buddhist intellectuals absorb the views of the conference on application of the development of the industrial revolution 4.0 of global social networks and the Internet, and apply application software in handling Buddhist affairs and preaching. of the church in a new era of creativity, a new era of connectivity, laying the foundation for a global Buddhist collaboration for female Buddhist intellectuals that brings great convenience to new opportunities such as Currently. That benefit has been motivating each monk and nun, especially the ranks of Buddhist female intellectuals in the role of Tathagata Messengers, and Buddhists clearly see their "duty" now as "Need to what must you do"? How to act? How can we grasp and integrate into the "Digital Era Communication Wave" while still maintaining the identity and bravery of a "Digital Tathagata Messenger" in the face of the massive onslaught of the storm? network storm! The urgent issue now is: "How can we actively promote the role of the monks and nuns of the Vietnam Buddhist Sangha in building a strong national unity block in the "Golden Time"? " of "Digital Technology Era"?

Disseminating the Dharma or spreading the Dharma has become one of the key and important tasks of the team of monks and nuns in the Vietnamese Buddhist Church in the present and in the future. The main purpose is to spread the teachings of the Buddha, bring peace and liberation to people. In addition, the characteristic of Dharma propagation activities is always flexible, especially associated with the spirit of the contract, the contract, the contract of the time, the contract of origin. In different eras, countries, and countries, monks and nuns must have a suitable method of propagating the Dharma, bringing the religion to life in a reasonable and successful manner. Today, the human world is being strongly affected by industry 4.0 , including Vietnam. Therefore, Buddhism in general and preaching work in particular cannot stand aside from the impact of modern and advanced industry taking place. Thus, what should our Buddhist female intellectuals do to adapt, match and promptly adapt to the 4.0 industry?

Whether the Buddha's teachings spread and develop depends on the "Messengers of the Tathagata". Buddhism has been present in Vietnam for over 2000 years, through many ups and downs, there have appeared the spirit of spreading Buddhism widely. But today, when the 4.0 technology era develops like a storm, leading to rapid changes in all areas of life, spreading the Buddhadharma becomes a big challenge for today's Dharma propagation.

Appreciating and utilizing the resources of Buddhist female intellectuals (Buddhist nuns and female Buddhists) in the Industrial Revolution 4.0 in all fields is meaningful not only to the Vietnamese Buddhist Church but also makes an important contribution to focus on the cause of industrialization and modernization of the country. Therefore, the role and position of female Buddhist intellectuals needs to be further confirmed, which will be the basis and foundation to promote the total strength of the Vietnamese Buddhist Church and the country in the current context.

The Industrial Revolution 4.0 appeared a period of innovation and integration in our country. Buddhist preachers have a great opportunity to reach out to Buddhist followers and Buddhist researchers, as well as Buddhist studies at home and abroad through mass media. on the one hand, social networks to learn, foster and supplement knowledge of the Buddha Dharma on the one hand, and on the other hand, to easily and effectively transmit and propagate the Dharma to the masses and fellow Buddhists.

On the occasion of the launching ceremony of the VIII term, the Central Committee for Dissemination of the Law has launched the Information - Live TV channel "Hoang Phap Online TV" - An application to install on the phone to watch and listen to the Dharma directly on the phone and Audiovisual equipment. This is a great opportunity to propagate the Dharma in the new era. And this is also a remarkable achievement of the Dharma propagation industry in the new term.

In the era of the flat economy of globalization, spreading the Dharma is not just about performing prayer rituals; or lectures according to regional customs, but we must have new methods, new styles, and breathe new flow of Buddhist thought into practical life, making Vietnamese Buddhism today. Modernity must be widespread and universal in the world.

\section{Research Methods}

We base on the methodology of dialectical materialism and historical materialism, together with the using basic research methods such as analysis - synthesis method, logical - historical method, interpretation - inductive

\footnotetext{
${ }^{1}$ Direction of Buddhist activities for the VIII term (2017-2022)
} 
method, comparison method, comparison, ... as well as inheritance of data. from published works of scientists.

\section{Research content}

\subsection{The role of female Buddhist intellectuals in Vietnam}

Right from the time it was introduced into Vietnam, Buddhism has been enthusiastically received by the masses of people and Buddhist followers because Buddhist thought is very close to the culture and beliefs of the Vietnamese people with values. ethical values, Buddhism such as: the spirit of compassion, joy and forgiveness, saving suffering and rescue, loving people as if you love yourself, very close to the sentiments of the Vietnamese people. The Buddha's idea of "compassion, charity, selflessness and altruism" was blended with the thought of patriotism and humanity of Vietnam. The birth and development of the Central Committee of Nuns under the Central Committee for Increase in Public Affairs is an objective necessity. Vietnamese nuns have recently contributed to the development of the country and the church. Through the Buddhist congresses, it can be seen that the nuns increasingly assert their role in the fields of activities in the Church.

Nuns are a part of Buddhist monks in general and Vietnamese Buddhism in particular, including a contingent of female Buddhist intellectuals who are committed to the religious life for the cause of spreading the Dharma. benefit of the Buddha. In the development of modern society in the era of industrial revolution 4.0, nuns are as equal as monks who are contributing every day and every hour to the common cause of the church, committed to serving the worldly ideology of the Church. Buddha, serving the Dharma and the nation. The role of Vietnamese Buddhist intellectuals; The impact of the industrial revolution 4.0 on Vietnamese Buddhism in general and Vietnamese nuns in particular. The Buddha was the first to lay the foundation for the movement for equality between men and women in society, so continuing to promote the role of nuns is essential in order to continue the good traditional network, develop Going up in all aspects is one of the focus of the Vietnamese Buddhist Church.

The nun is a person who strictly observes the precepts, deeply understands the teachings, and often brings the Buddha's teachings to Buddhist followers and the people. A nun is a peaceful person who looks down on life and death. Continue to bring the Dharma to people across the country. To do that, the nuns over the years have always focused on teaching and training nuns, building pagodas, and nurturing them.

\subsection{Female Buddhist intellectuals in Vietnam in the 4.0 revolution}

In addition to the opportunities, we are also facing great, thorough and fundamental challenges in the present and in the future before the 4.0 technology revolution, which is shown as follows:

Challenges from the need to train a team with professional qualifications in information technology to be in charge and manage the online teaching program and do group work; economic needs to equip infrastructure; The need for professors, in addition to cultivating Buddhist knowledge and teaching skills, must also equip themselves with a certain ability in information technology and continue to supplement and upgrade their technology level to meet the needs of teachers. the flexibility and urgency of the new technology. In particular, the Hoang Phap family also had to practice soft skills such as communication and teamwork.

Improving foreign language skills, especially English: In acquiring knowledge and applying new technologies, it is required that the French preacher must have a basic level of English. And the need is even higher, as a messenger of the Tathagata in the cause of promoting the Dharma, it is necessary to be fluent in English or some common living languages in addition to the native language. Only then will it be easier to create sympathy, to be able to achieve and to penetrate into overseas Dharma teaching environments.

Sakyadhita Conference - The World Nuns Conference was established in 1987, bringing together all the nuns in Buddhism to create the highest development of Buddhism through the role of nuns in the Church. Vietnamese Buddhism, with the permission of the Government, organized the 11th World Nun Conference from December 28, 2009 to January 3, 2010 at the Cultural Center of the Buddhist Association of Ho Chi Minh City. Ho Chi Minh had great success.

Currently, in Vietnam, Buddhist intellectual monks and nuns nationwide have more than 600 doctorates, thousands of masters and bachelors, mainly trained in India, China, Taiwan, Japan, Korea and Vietnam. Among them, female intellectuals with doctorate and master's degrees are more and more numerous than in the past. In addition, some female Buddhist intellectuals have overcome all difficulties and prejudices to go to graduate school and graduate school in some countries around the world (India, Sri Lanka, Korea, Japan, etc.). . ) in many different scientific fields: Buddhist philosophy, Religion, Linguistics, Psychology, Medicine, ...... It can be seen that, compared with other branches and fields such as female intellectuals, Buddha The number of religions is still modest, but this is a remarkable achievement of the Nuns' Sub-Committee and of the Vietnamese Buddhist Church compared to international Buddhism and some other religions.

In the era of technology 4.0, the international integration of Vietnamese nuns has gradually "entered the world with the tools of the new industrial era, digitizing and applying the world of the Internet and modern 
media. means, always and immediately, for Buddhists to have access to the Buddhadharma."1. With the aim of promoting the image of Vietnamese Buddhist women alongside Buddhist women in the world, in domestic practice and leadership as well as supporting international Buddhist missions, many Buddhist leaders have been confirmed and discovered. Distinguished nuns in the history of Buddhism in Vietnam and other countries; for the nuns to actively promote and transmit the Dharma and the nuns' ability to enter the world to serve; encourage the development of female Buddhist intellectuals; enhancing the cohesion of the Buddhist female community; upholding the middle way lifestyle; love and respect for the protection of the environment; encourage the development of young nuns to be familiar with 4.0 technology; respecting the national cultural identity in accordance with the spirit of Buddhism; respect the Buddhist practice methods of the sects; praising the role models of nuns in modern times. Typically, Vietnam has Nun Tri Hai, Nun Dam Tin, Nun Dam Huu, Nun Huynh Lien, Nun Dam Xuong, .... known to the world, proving that Vietnam has always had outstanding Buddhist children who are very sensitive to reality and always ahead of the times. International nuns understand more about Vietnamese Buddhism and the contributions of female Buddhist intellectuals to affirm, exchange and cooperate internationally. Through three United Nations Vesak celebrations, Vietnamese nuns have contributed significantly in the fields of academics, charity, design, and diplomacy. Especially in the 4.0 era, many nuns apply it. successful advances of science, technology and technology in the propagation of the Dharma, contributing to bringing the image of the country and people of Vietnam to international integration. Many nuns study abroad because they know many different languages and have very good teaching, writing and service skills, because they are fully equipped with Dharma study and practice. Success is all based on the foundation of precepts and the spirit of six peace.

Currently, with the strong development of Industry 4.0 with its great advantages, Vietnam also applies the great benefits brought by Industry 4.0. Speaking at discussions and dialogues at the World Economic Forum (WEF) Annual Meeting in Davos, Switzerland from January 22-25, 2019 according to the Executive Chairman and Mr. Founder of WED, Professor Klaus Schwab, former Prime Minister Nguyen Xuan Phuc said: "Industrial revolution 4.0 has knocked on the door of every business, bringing profound changes, which no country can stand aside. Efforts to overcome difficulties, limitations and challenges, Vietnam sees this as a great opportunity when countries compete with creativity, not only with traditional factors such as free trade, scale, etc. , experience, labor, investment capital". Vietnam has launched the "Make in Vietnam 4.0" program, piloted the 5G network in 2019 and commercialized it in 2020, making Vietnam one of the leading countries in the world in $5 \mathrm{G}$ deployment. It is an information technology promotion initiative based on new policy, new management thinking and new technologies. To advance to the 4.0 technology revolution. The impact of the 4.0 technology revolution on Buddhism, Vietnamese Buddhism has existed and developed for more than 2000 years, with the spirit of entering the world blended with the nation's destiny. The Vietnamese Buddhist Sangha for nearly 40 years (1981 - 2020) with the motto "Dharma - Nation - Socialism", always accompanies the nation, Buddhism applies the influence and impact of technology 4.0 in the works of "Buddhist work and propagating the righteous Dharma for the benefit of all living beings"...

Applying 4.0 technology to the organization and management of the work of the Church, and the departments, branches, institutes,... Systematic unified management from the Central Buddhist Church to all levels of the Buddhist Churches provinces and districts in terms of organizational structure, personnel and assets, if digitized software is applied, and features are installed for interconnection; or used to send administrative documents of the Church at all levels. Applying the good method of science and technology 4.0 to the organization and management of the human resource and administrative system to ensure the promptness of results. But to control the entire system of the above information, to avoid data theft, to gain control of the system, there must be safety protection measures.

Applying 4.0 technology to education and training, in the education system of the Church, "the whole country has 35 Buddhist intermediate schools, 8 Buddhist colleges, 8 Buddhist institutes"2. Currently, some schools have just applied the electronic library system in the learning and searching process of monks and nuns, while some schools do not have an electronic library system to help monks and nuns with problems. study. Currently, the country and the world have gradually applied teaching methods applying information technology and digitizing knowledge, making full use of learning and research, which can immediately look up, use on media such as computers, phones when having access to those data warehouses, making it convenient to study, look up,...

Charity work for social welfare, this is an aspect that is often seen as a clear incarnation of Buddhism. Selfless volunteering is an attribute of Buddhism. Buddhist charity activities can be commemoration, visiting and encouraging unfortunate individuals in the hospital, paying tribute to people with meritorious services to the country during holidays, and establishing youth clubs. Buddhist families, skills training courses... are sponsored

\footnotetext{
${ }^{1}$ Tran Nhan Tong Institute (2018), Incarnated Buddhism and contemporary social issues, Hanoi National University Publishing House, pp.18.
} ${ }^{2} \mathrm{http}$ //phatgiaobinhdinh.vn/giao-duc-phat-giao-muc-tieu-nhung-giai-phap-thuc-hien. 
by monks and Buddhists, when they know how to take advantage of the positivity of the internet in launching and promoting images in social charity activities.

The teaching and communication of Buddhism are closely related. To propagate the Dharma is to develop and make the Buddha Dharma spread to human society in many different ways. Communication in that narrow sense is a form of preaching the Dharma by special means, applying modern information technology, in order to spread the introduction of Buddhism. Therefore, the development of the 4.0 technology revolution with its characteristics will be of great help to spreading the Dharma and helping the communication work.

Nuns are an integral part of Vietnamese Buddhist monks, engaged in Church work, in almost all aspects of their activities. With the development of the current 4.0 technology revolution, Vietnamese Buddhist nuns are affected by certain influences, on positive and negative aspects. It can be mentioned in such aspects as the awareness of nuns about the 4.0 technology revolution. Currently, most nuns realize the importance of science and technology in the process of practicing and spreading the Buddha's teachings. This is an activity that keeps up with the trend of the 4.0 technology revolution era. In addition, the impact on the use of social networks, the use of electronic devices with internet connection, and the exploitation of big data (Big Data). These are the values that modern science and technology bring. However, if you take advantage of the excessive use of electronic devices on websites with content contrary to Buddhist teachings, it may cause some monks to be affected by its erratic and wrong habits, affect the entire practice. Therefore, the use of modern science and technology needs careful attention and selection.

The achievements of the industrial revolution 4.0 will contribute to supporting Buddhism in organization, management and education activities, preaching the Dharma, culture, and communication..., contributing to bringing Buddhism closer to daily life. , the life of Buddhists and people.

\subsection{Solutions to promote the role of nuns in modern society in the era of technological revolution 4.0}

Nuns are an integral part of the development of Vietnamese Buddhism. In order to further promote the role of Vietnamese nuns in the current 4.0 technology revolution, in our opinion, Vietnamese nuns need to focus on the following points:

Firstly, it is necessary to raise awareness of Vietnamese nuns about the stormy development of the 4.0 technology revolution. The inevitability of the modern scientific and technical development of the world; raising awareness and adaptation of nuns on the rational, effective and selective use of modern equipment for the process of practicing and propagating Buddhist teachings. This requires the pioneering of reputable nuns, nuns, and nuns who do the work of teaching, guiding practice, choosing content, programs, measures, knowledge, and appropriate behavior. with Buddhist teachings, complying with Vietnamese law.

Secondly, through teaching activities, social charity activities, the nuns have a pervasive impact on the mass of Buddhist followers about the role, positivity as well as the negative side of the 4.0 technology revolution. on moral values, in accordance with national culture and identity, taking Buddhist precepts as the basis.

The 4.0 technology revolution will change not only what we do but also ourselves in terms of personality, cultural identity, health promotion, appropriate use of time for work, entertainment, etc. In the past, Dharma lectures and training sessions need to be oriented for Buddhists to be properly aware of the 4.0 technology revolution, to perfect themselves in terms of "personal and oral teachings" to dignify the Church, respond timely response to the trend of modern society.

Third, the nuns themselves need to constantly study and "wisdom vision" with wisdom as a career. Since the time when the Buddha Nun Sangha was established, it was a great opportunity for nuns to have the condition to "advance the dignity of the body". This is a great grace that the Buddha gave to the nuns. In order to show gratitude to the Buddha, nuns need to make every effort to strengthen their bodies and minds, cultivate virtues, uphold the precepts and follow the Buddha's teachings to stay firmly on the path of cultivation and knowledge. about foreign languages and information technology, the ability to use high technology in their practice. This is also the propagation of the Buddha's righteous Dharma. It can be affirmed that if using information technology to propagate the Dharma, it will certainly bring the light of the Buddha's teachings to many people in the fastest way. Thus, compared to the traditional preaching of the Dharma, this is a big and inevitable revolution of the 4.0 technology revolution. The truth that the Buddha enlightened has actually stood firm in all ages, unaffected by the progress of time and the intellectual growth of mankind. Therefore, no matter how much scientific knowledge develops, the Buddha's teachings are still far beyond the discoveries of mankind. However, in order to propagate the Dharma well in the period of integration and development, especially in the current era of rapid development of technology 4.0, Buddhist evangelists really have to pay attention and promptly grasp it. , applying new technologies, finding solutions to suit the actual needs of a society undergoing digital transformation in all fields. Only in this way will the Buddha Dharma bring about great results in the cause of profit-making. Thus, the new team of Buddhist monks and nuns brings benefits in inner transformation and spiritual sublimation, especially in the spiritual aspect for Buddhists and people in the midst of their materially prosperous society. Industry 4.0 era. This has made us think and ponder for many years with the desire to spread 
the Buddha's light everywhere and how to take advantage of this 4.0 industrial revolution achievement, to capture and create the propaganda strengths of the new era and help to overcome the social consequences of the industry that will occur.

Female Buddhist intellectuals, while teaching the Buddhadharma, need to increase their learning and skills related to information technology and how to use modern electronic devices. Today's preaching of the Dharma is not only preached on the court and attended by the public, but also through social networking sites Facebook, Zalo, youtube, etc. to bring the teachings to the masses, especially those who are busy. Busy, they do not have time to go to the temple so that they have the opportunity to study the Buddha's teachings. Over the years, I have noticed that many teachers have successfully applied this. Thanks to the achievements of the 4.0 revolution, the wonderful teachings of the Buddha reached the vast majority of the population much deeper than before, including people in remote rural areas, high mountains and border areas. dangerous world. We need to promote and multiply these models further, which is practical work to meet the four great graces.

Images of monks and nuns appear more and more in the media. Society increasingly understands the position and role of the monk with the mission of practicing liberation and entering the world to practice religion. Therefore, in interacting with the media, monks and nuns need to show the dignified, elegant dignity of the monastic, and avoid putting images that are unintentionally offensive or uninformed by those who do not understand. Buddhism spread, affecting the Sangha in particular and the Church in general. This actually happened.

Today's media world is a multi-dimensional, multi-information world. Therefore, monks and nuns need to choose their strengths to suit the characteristics of different social groups (youth, students, workers, farmers, businesses, entrepreneurs, corporations), office workers,...). On the other hand, teaching through the media today needs to be very concise, coherent, logical and inspiring to the masses because many people do not have much time. Therefore, monks and nuns participating in lectures need to know how to arrange their thoughts appropriately to easily go deep into people's hearts, inspiring them to practice more practically with life.

When preaching the Dharma, we need to sit together with seminars to draw up plans to provide material and spiritual support to social and occupational groups that are prone to unemployment in the future and groups of people. disadvantage in society due to the consequences of the 4.0 revolution. In other words, they are vulnerable groups that desperately need our compassionate help. In my opinion, Buddhism needs to have measures to support them in many ways such as: livelihood transformation, skills education, counseling, psychological support, awareness, orientation for stability and life balance. in a new way of life. Thereby, we will direct them to the Dharma, to the Buddhadharma easily. Thus, in the 4.0 revolution in Vietnam, Buddhism will hold an important role and position for the people, as well as having been attached to and accompanying the nation for more than two thousand years of building the country and keeping it safe. country.

This 4.0 revolution will make people communicate and interact with each other more. But communication is mainly through electronic devices, communication networks that have little chance of direct contact with each other. Thus, I want to emphasize that this will reduce the humanity in society? Whether the culture of human-tohuman communication to learn about morality, personality, and lifestyle will fade before the phenomena led by the media. I think a lot about this. Disseminating the Dharma through the media is the rule and the top goal of female Buddhist intellectuals. But teachers also need to contact, experience, and share directly with Buddhists and the social community so that we can approach and explain not only with the teachings of the mind, the teachings but also the teachings of the body. . I think this is something that Buddhist female intellectuals need to pay attention to. For example, we talk about $\mathrm{Vu}$ Lan festival through the media, many people know its meaning and value. However, how do they go to the temple, directly put roses on their clothes, attend the spiritual ceremony, listen to the teachings of the abbot, they will overflow with the emotions of the children for the two parents. mine. Vu Lan festival goes into people's hearts, stays in their hearts for a long time.

Buddhist female intellectuals should try to create a facebook or zalo for the temple to post temple activities and lectures quickly to Buddhists. To connect with the practice ashram of the temple, as well as timely capture the thoughts, aspirations and desires of Buddhists. We need to create a group to understand and at the same time guide them to practice in a healthier, easier and faster way, to help them have a peaceful and happy life right here in this world.

Acting Minister of Information and Communications Nguyen Manh Hung emphasized that: In the 4.0 era, learners need to integrate multidisciplinary knowledge. The opportunity lies in linking different industries and knowledge. Everyone was very pleased with this statement of his. Therefore, modern Buddhist women need to learn more, understand more, integrate and master multidisciplinary knowledge, from Buddhism to the social sciences and humanities, natural sciences, as well as other knowledge. to meet the needs of spreading the Farectification in the new era. In particular, in the mission of training monks and nuns who are studying in advanced - intermediate classes of lecturers, the Organizing Committee will try to change the training content to meet this trend.

Currently, the Vietnam Buddhist Sangha, Office 1 in Quan Su Pagoda - Hanoi, Central Office 2 in Ho Chi 
Minh City, has an online Buddhist TV channel, launched the Digitalization Working Group. Church events. This is a vivid change in the Church's preaching work, partly responding to the stormy development of 4.0 technology. However, in our opinion, that is not enough, but we must apply and apply more, to be able to develop and meet the Buddha's work in the future.

The Central Department of Propaganda of the Vietnam Buddhist Sangha intends to organize a national Dharma propagation training course at Bai Dinh pagoda in Ninh Binh. But because of the Covid 19 epidemic, on July 13, 2021, the online Dharma center has to organize a total of 30 days, every day at 13:30 to 15:30. And from $8 \mathrm{pm}$ to $9 \mathrm{pm}$. That is the flexible benefit in spreading the law in the 4.0 technology era.

The application of technology 4.0 to study without paper books: Take advantage of the results of 4.0 technology and seek support from the online learning portal system to apply it to the teaching and learning system at the Buddhist Academy. in general, and the Senior High School class, Professor in particular. When accessing this system, monks and nuns will have access to hundreds of thousands of lecture banks, lecturers, the latest textbooks anywhere, on any technology device to help increase the interest in learning. study process. Besides, also open online courses.

To take advantage of the achievements of the Industrial Revolution 4.0, first of all, female Buddhist intellectuals must build an online website; digitize Hoang Phap's information technology infrastructure at the grassroots level, by putting it on the cloud computing system; To digitize data, documents, information of the Dharma, and communication industry, we must know how to use smart software with Internet connection and maximum internet application with everything.

Industry 4.0 is knocking on every door, leading to rapid and far-reaching changes in all areas of life. The most obvious impact is the emergence of robots with artificial intelligence, with features that can replace humans, even more optimally, such as the ability to calculate, analyze, and remember, which can act as roles. Lawyers provide legal advice online quickly. Therefore, female Buddhist intellectuals must grasp this achievement to apply in the work of livestreaming the lectures of the lecturers. It can even be used to directly answer the problems of studying Buddhism for those who study and study. Artificial intelligence also helps the preacher in quoting and sourcing for lectures, analyzing the trends of the times to have lectures that are realistic but not far from the teachings of the Buddha.

Using cloud technology: To store the entire system of the Tripitaka Buddhist scriptures and store the teachings of the teachers. Lecturers must know how to approach the 4.0 revolution to exploit materials, refer to using the electronic lesson plan system, to prepare lessons and give lectures more conveniently and better. Buddhist learners only need a smartphone, then the treasure of Buddha's teachings is in their hands

With Big Data (big data), it will provide solutions for us in studying the interests, habits, and behaviors of the object of the Dharma, thereby indirectly helping the preacher to achieve good results on aspect of the contract.

- Develop a project to strengthen the application of information technology in management and support teaching activities in the High School - Middle School classes, contributing to improving the quality of teaching and training of teachers.

The style and practice of inner transformation of the Dharma evangelist: Whether or not Buddhism can survive and develop is largely thanks to the Dharma practitioners and female Buddhist intellectuals. Therefore, it is required that Tathagata messengers must meet the basic qualities of a monk. In parallel with cultivating knowledge of the Buddhadharma, it is necessary to have the effort of self-cultivation and practice of the four positions. Because the quality of the preachers plays a very important role in the propagation of the Dharma, because the influence of Buddhism is positive or negative, strong or weak, extensive or limited, always depends on ethics, level of knowledge, especially the strength of this team's inner transformation practice.

In short, the Buddhist preacher, including the ranks of female Buddhist intellectuals with the 4.0 revolution, must really be those who wear the Tathagata robes, sit on the Tathagata's throne, and stay at the Tathagata's house. assigned by the Tathagata.

\section{Conclusion}

Finally, I want to summarize that the industrial revolution 4.0 is a trend, a great progress of mankind that no one can reverse. For the group of female Buddhist intellectuals who carry the responsibility of holding the torch of the Dharma, with the wisdom of the Buddha's daughter along with the spirit of contract, contract, time and land, it is very necessary to learn and grasp capture and take advantage of the achievements of this revolution to apply in the field of dharma propagation. By doing so, we will effectively propagate the wonderful teachings of the Buddha in the civilized age with the advanced achievements of science and technology.

However, with my own experience, I would like to emphasize that no matter how human civilization develops, no matter how our society changes, the practice and cultivation of the Three Immortals, the aspiration Birth and the path to liberation and enlightenment are still the end for each person, for Buddhist monks and nuns as well as for the whole society. 
Therefore, the ranks of female Buddhist intellectuals must try to grasp 4.0 technology to apply in the mission of preaching the Dharma, but we still do not forget to promote the core values and quintessence of the lively German teachings. The Ton. The source of peaceful energy in body and mind, a great wisdom, an unselfish view of selflessness, tolerant of all dharmas, helping people to be peaceful and happy, transforming afflictions, getting out of suffering, samsara birth and death.

In recent years, with the attention of the Central Church, the Vietnamese nuns have made constant efforts to accompany the development and integration process of the country. Currently, Vietnam is having a strong rise, connecting with countries around the world is inevitable in the period of international integration, the era of the 4.0 technology revolution. Vietnamese nuns have been taking specific actions to affirm their position and importance through organizing events, scientific conferences, organizing Buddha's Birthday, Vu Lan's filial piety ceremony. ... In particular, successfully organized the use of information technology with the online Buddhist website, An Vien TV station, phattuvietnam.net, online Dharma center, ...

In the coming time, on the next step of the development of Buddhism, it is necessary to have a more correct and realistic view of the role of nuns in order to promote a clear perception as "beneficial and beneficial for the world". Thus, we can take advantage of the gray matter of female Buddhist intellectuals in the church and society, while demonstrating the Buddha's equality truth, and building a current Sa Ba world that is peaceful and happy. and sustainable development. In addition, it is necessary to promote the bright examples of Buddhist nuns in social activities, to associate the Dharma with the nation, which needs to be recognized, honored and encouraged by the Church and society in a timely manner. Encouraging female Buddhist intellectuals to actively participate in the development of the country, constantly making efforts, striving to bring Vietnam to integrate with the trend of the 4.0 technology revolution. It is also a practical job to repay. The three treasures and the four great graces. Praying for the blessings of the Buddhas in the 10 directions to bless the country of Vietnam and the whole world soon to repel the covid 19 epidemic, return to normal, and make Vietnam peaceful. flourishing and rivaling the great powers of the five continents.

\section{REFERENCES}

1. Central Committee (2008), Resolution No. 27-NQ/TW, dated August 6, 2008 on building a contingent of intellectuals in the period of accelerating industrialization and modernization. Presented by the Xth Central Committee, Hanoi.

2. Ministry of Science and Technology (2017), "Report on Industry 4.0”, April 2017.

3. National Bureau of Science and Technology Information (2017), Summary of the Fourth Industrial Revolution, Hanoi.

4. Edward Conze, Nguyen Minh Tien translated and annotated (2005), A brief history of Buddhism, Ho Chi Minh City General Publishing House.

5. Prime Minister of the Socialist Republic of Vietnam Nguyen Xuan Phuc (2019), Speech at the World Economic Forum (WEF) in Davos, Switzerland.

6. Thich $\mathrm{Nu} \mathrm{Tu}$ Thao (2016), Brief History of Nuns and Behavior of Vietnamese Buddhist Nuns, Ho Chi Minh City Culture and Arts Publishing House.

7. Le Van Thang, Nguyen Van Tuan (2020), Vietnamese intellectuals with the industrial revolution 4.0, Publishing House. National Politics Truth, Hanoi.

8. Tran Nhan Tong Institute (2018), Incarnated Buddhism and contemporary social issues, Hanoi National University Publishing House. 